\title{
From the Gaming Experience to the Wider User Experience
}

\author{
Eduardo H. Calvillo Gámez \\ UCL Interaction Centre \\ University College London \\ London, UK \\ e.calvillo@ucl.ac.uk
}

\author{
Paul Cairns \\ Dept. of Computer Science \\ The University of York \\ Heslington, York, UK \\ pcairns@cs.york.ac.uk
}

\author{
Anna L. Cox \\ UCL Interaction Centre \\ University College London \\ London, UK \\ anna.cox@ucl.ac.uk
}

\begin{abstract}
In this paper we discuss the different elements of the gaming experience and their relation to other concepts within HCI. The objective is to showcase how the different elements that form the gaming experience can be used to understand further issues regarding user experience. The objectives of games are, after all, to provide players with a positive experience. Understanding the elements that eventually lead players to have a positive experience should provide feedback about the wider user experience concept. Although video-games and non-game applications seem to be two different domains of study, in terms of experience, they both aim to improve the individual's experience.
\end{abstract}

\section{Categories and Subject Descriptors}

H.5 [Information Interfaces and Presentation]: Miscellaneous

\section{General Terms}

Human Factors

\section{Keywords}

User Experience, Video-Games, Theory, Games

\section{PUSH START TO BEGIN}

Games are fun to play. Their objective is to provide participants with a positive experience; people engage with games freely and with no more motivation than having a desire to enjoy themselves. But game-players do not only gain an enjoyable time; they also learn, share and form culture [8]. There is a trend in which game-like applications are being developed to provide something more than a positive experience [15]. Such efforts are directed towards using learned concepts to improve games, rather than learning from games *Also at División de Nuevas Tecnologías de la Información,
Universidad Politécnica de San Luis Potosí, México.

(C) The Author 2009.

Published by the British Computer Society to improve what we know. This has changed a little overtime as there is a strong argument to consider video-games as a source to learn about learning [6].

One of the first from the findings from game research was that games are hard to define; for example, Juul [10] reviews many definitions in order to propose a new one. Regardless of all the complexity that scholars may face in finding a suitable definition for games, individuals are able to recognize a game when we see one. That is, games are not really defined in terms of their physicallity, but in terms of the experience they provide.

Video-games, or computer-games, are games played with the help of technology. Historically, the game has been implemented in a computer using the monitor to represent the status of the game; the CPU of the computer to enforce the rules of the game, or play as an opponent; and the input devices (mouse/keyboard/etc.) to manipulate it. Although these are still the main characteristics of video-games, pervasive games are pushing the boundaries of the actual use of video to play video-games. Once games were implemented into their video-game form, they became a topic of concern for computer scientists and engineers: designing better graphics, better AI, better networks, etc. It eventually became a domain for HCI [22]. All the methodological arsenal of HCI is currently being devoted into improving videogames.

Also, HCI is developing a growing interest in understanding User Experience (UX) [14, 11]. The scholarly study has been bumpy in trying to understand the concept and then design and implement applications that have UX at its core. So, what about if we look at it from the other perspective? Games are about providing a good experience. So, what can we learn about the experience in video-games that can be used to improve the understanding of experience in HCI?

In this paper, using the Core Elements of the Gaming Experience (CEGE) theory $[2,3]$ as a guideline, we argue that the discussion over user experience could benefit greatly from learning from the experience of playing video-games. The paper presents the interactive elements of the CEGE theory; first discussed within the game context and then within a non-game environment. The theory provides a robust explanation of the experience in video-games, which is discussed below. The paper describes how a positive gaming experience is formed. And then, by exploring the different elements in relation to non-gaming experiences; it strongly informs thinking on UX by providing an account of a successful UX in a non-gaming context. The paper is divided in five sections, first we present the model for the gaming 
experience, and then we discuss the three main elements of the model: control, facilitators and ownership. The paper closes with our conclusions.

\section{THE CORE ELEMENTS OF THE GAM- ING EXPERIENCE}

CEGE are the hygienic factors of the gaming experience. Hygienic factors [7] are necessary but not sufficient conditions. The gaming experience is the one-to-one relationship of the player with the game; once the player starts engaging with the game. Thus, the CEGE are the necessary but not sufficient conditions to provide a positive experience. If they are present, then there is no guarantee that the experience will be positive, but if missing, then the experience will be negative. The CEGE take a narrow view of everything that could involve the experience of playing video-games. It does not look at why players select a certain game [20], or how social interactions affect the experience [13], or which type of fun the player seeking [12]. The core elements are just part of the process of playing the game; it is how the player builds the interaction in order to achieve a positive outcome.

The CEGE are presented in a hierarchical model. The two main components of the model are the actual video-game and the interaction of the player with the game, which we call Puppetry (Figure 1). It is the combination of these two that leads to a positive experience.

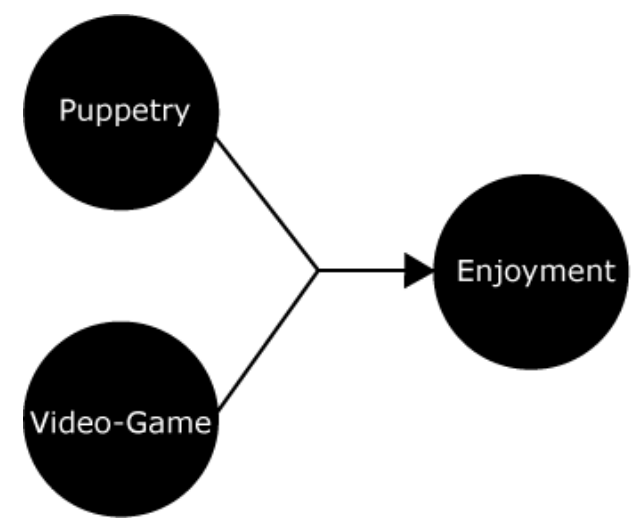

Figure 1: The CEGE Model: Video-game and Puppetry are needed to reach and enjoyable experience

The video-game is the tool needed to engage with the game. The video-game is how the player sees the game, and it is formed by the environment and the game-play. The former is the body of the game while the latter is the soul. Environment is perceived via the graphics and sounds. Game-play is defined by the rules and the scenario that covers those rules. See Figure 2.

The interaction process, named Puppetry, leads to the enjoyment when the player gains control of the game. After getting control, then player then takes ownership over the game. That is, the actions happening on the game are the result of the player efforts. Control is aided by a set of facilitators that can also help the player reach a sense of ownership. Ownership is what eventually leads to positive experience (see Figure 3).

The player needs to first get control of the game. There are six items that define the control of the game: controllers,

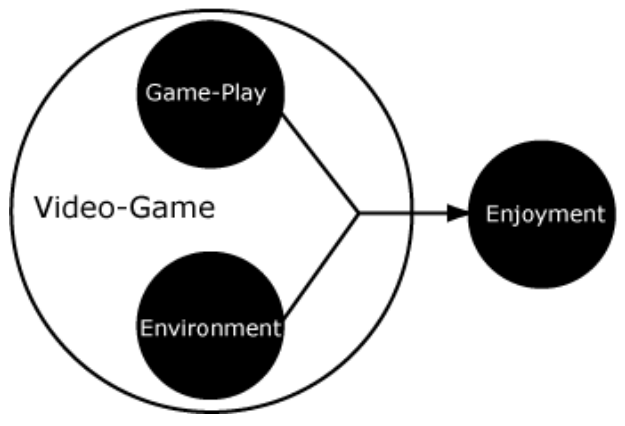

Figure 2: The CEGE Model: Video-game is formed by the game-play and environment of the game.

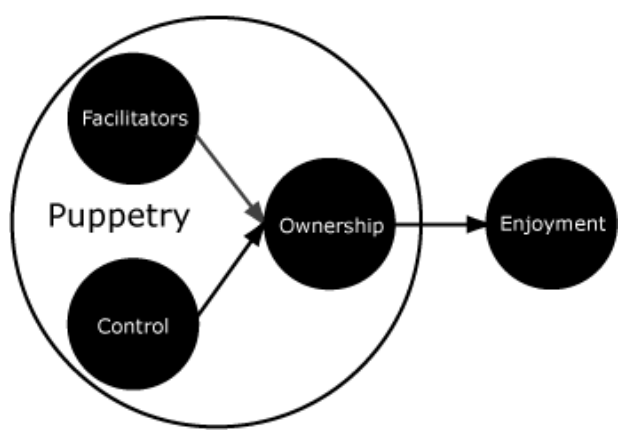

Figure 3: The CEGE Model: Puppetry represents the interaction of the player with the game.

small actions, memory, point of view, something to do and goal. Controllers refer to the actual input device used; can the player actually use them? Small actions are the actions that the objects in the game can perform, and specially, how they relate to the controller. Memory is about the player remembering all the actions and the mappings into the controllers. Point of view is what the player can actually see in the screen and how it can be seen. Something-to-do refers to keeping the player occupied. And goal, which is what the player is supposed to do, even if vaguely at the beginning.

Then there are the facilitators. These are elements foreign to the game, but that come with the individual. How much time has the player to engage with a game? May be only 5 minutes a day, so playing Starcraft is not an option. Previous experiences, what about those games the player had used before? May be the current one is not so good, but because of the previous one the player is still happily engaged with it. Finally, aesthetics values, there is something in the game that appeals to the player.

Finally, there is ownership. Ownership is formed by big actions, personal goals, you-but-not-you and rewards. Big actions is when the player uses the small actions in order to do something, he puts them together to create his strategy. Personal goals are the extra goals that the player creates while playing a game, there is still a main goal to be met, but something on the side is always good. Rewards are about the game giving kudos to the player every so often; it is the game acknowledging the player's ownership. And youbut-not-not-you is giving the player a cathartic moment in order to become, or do, something out of the everyday life.

All these elements and interactions are needed in order to 
achieve a positive gaming experience. But these elements are not exclusive to the video-game domain. They are already part of the HCI literature in different aspects. They have been studied for the design of different applications. In the following sections, we discuss the three elements that form puppetry; only this time, we propose how these elements would adapt to the wider UX by looking to non-game contexts.

\section{ON CONTROL}

Game is what we play, video-game is how we play it. There is a difference between playing the game and controlling the video-game. Playing refers to the whole of the interaction, controlling refers to the six elements described above. Instrumental interaction [1] looks at this duality. It provides a differentiation between the instrument that it is used and the task that is being done.

Instrumental interaction provides a differentiation between the actual devices used to manipulate the widgets of a GUI, versus the actual implications of such movements. In order to push a button, the user needs to go through the mouse to do so. Although most users would associate both activities as being the same. Once the application changes device, such as using a touch screen or a computer without a mouse, the application stays the same. The button stills needs to be pushed, but now, this can done be via the keyboard or by putting pressure on the surface of the screen. In the gaming experience this is also present: small actions and controllers. They provide a differentiation between what the objects in the game can do, and what the player has to do in order to do them. Further more, this relationship is also dependent on memory, can the player remember all the actions that can be done? And if not, does the interface help in bringing them to memory? This is basic usability and already discussed by Norman [17]. However, applications still do not help users in making the link between action in the screen and action in the real world.

Further more, to gain control, the game provides the player with a general goal. The player might not know the specific goal, but he has an idea of where to start. If normal applications want to improve the experience of the users, they should allow for a clear goal specification. Unlike a game, were the goal is the part of the game, in productive applications the user is engaging with the tool because there is a goal to achieve. The user is the one providing the goal, not the application. But, some times the user does not have a clear goal. This is where the application can learn from games: provide a way to clarify the goal of the user.

To gain control of video-games, the player also needs to feel that something is being done. There has to be something to do that keeps the player busy while the actual goals of the game are specified. This is something that gets lost in productive applications. Is it possible to keep the user active while reaching the goal? Could Word, for example, understand that it is necessary to provide a list taking application, in which the user could write the different words that describe what she is trying to write?

Finally, there is point-of-view. What the player is seeing has an influence on how the game is being understood. It is not the same to see the game in first-person as in thirdperson, each view procures a different reaction according to the information present. Do applications provide to the user all the information that is necessary? Do they let the user specify which information is needed at what moment but not at another?

\section{ON FACILITATORS}

In order to reach ownership, the player needs to have a sense of control. If control is poor, then facilitators are needed to reach ownership. Facilitators play to the subjective part of the player and are formed by previous experiences, time and aesthetic values.

Previous experiences influence the way we experience things in the future [4]. Nielsen [16] suggested keeping homogeneity when designing new interfaces. Jacob et al [9] suggested to take advantage of what the user already knows, and suggested a series of trade-offs between relaying less or more of this knowledge. These two examples showcase the use of previous experiences within HCI design, some of it may have to do with marketing and loyalty, but if a user has had a frustrating experience trying to use a tool, it is unlikely that the user will try the new version of the same tool. Time relates to how long the user is willing to try the tool. Raskin [18] already discussed this when he suggested giving the user a sense of the application being ready instead of being stuck. Taking time into consideration by allowing the user to think and engage with the application; do not require more of the user's time than is needed. Then, there are the aesthetic values of the application $[21,19]$. However, an application that is aesthetically pleasing is not necessarily providing a positive experience; unless the user is there to appreciate it.

Facilitators are a palliative to poor control. Eventually, they would wear off and bad control would lead to a poor experience.

\section{ON OWNERSHIP}

Once the player has control of the game, there is the opportunity to gain ownership. It is from ownership that there is a direct link to a positive experience. Would a user of a normal application feel that what is happening with the application is the result of her own actions?

The concept of ownership is somewhat similar to the concept of appropriation [5]. In order to have a sense of ownership in video-games, there are four different elements. Not all of them are applicable to different experiences, but they are still valuable to explore.

Starting with those elements that are not directly related to productive applications. Video-games allow players to experiencing a cathartic moment, a you-but-not-you moment. It would be ridiculous to argue in favour of something similar in productive applications. However, they should provide the opposite to users. A user engaging with an application to perform a task should be proud of the work being done, he should be able to become a super-me. Rather than youbut-not-you, the application should provide a you-as-youwant-to-be.

Next, there are rewards. Rewards let the player know that the game is acknowledging that is being owned by the player. Productive applications should also provide a sense of progress. Let the user specify the goal, and then start marking how far forward the user has moved towards that goal. Let the user know when he is going in the wrong direction, and not, do not delete their whole work and make them start the level again, rather, allow them to track their progress, and understand when something went wrong. 
Then there are big actions. Let the user use all the small actions that the application provides to complete the goal. Do not limit her. Allow her to use Word documents as scratch paper, let her to use SPSS to sort information. The user knows better than the application what it is that she is trying to do; if the small actions permit it, let her do a big action.

Last, there are personal goals. In a game, the player may alter the main goal in order to complete a secondary one not vital for the game, but important for the enjoyment. In productive applications, let the user create small goals, write paragraphs under a certain time, write a second paper while writing a first one. Do not hug all the recourse, give the user freedom to, once a goal is defined, explore other goals.

\section{GAME OVER}

The objective of this paper was to enrich the discussion of User Experience by looking at the experience of playing video-games. Of the three main components that have a direct effect on the player's interaction with the game, control, ownership and facilitators, ownership is the one to keep an eye on.

Several of the concepts related to control and facilitators are old or have been taken into account before. Ownership, on the other hand, relates to the somewhat newer concept of appropriation. Ownership, formed by big actions, you-butnot-you, rewards and personal goals, should be the objective when designing for experience. Designers should provide applications that would facilitate the users making the application their own. The application should help the user in clarifying the goals, in rewarding, and in helping the user become proud of the task they have completed.

In other words, what normal applications should learn from games is to pay attention to what the user is trying to do, and help the user make the tool his own in order to do so. It is not about the interface, application or tool; it is about the user's needs. Just as in games, if the player wants to have fun, he just has to play the game, regardless of its form. And then, game on!

\section{ACKNOWLEDGEMENTS}

Eduardo H. Calvillo Gámez's research is sponsored by SEP-PROMEP.

\section{REFERENCES}

[1] M. Beaudouin-Lafon. Instrumental interaction: an interaction model for designing post-WIMP user interfaces. In CHI '00: Proceedings of the SIGCHI conference on Human factors in computing systems, pages 446-453, New York, NY, USA, 2000. ACM Press.

[2] E. H. Calvillo-Gámez and P. Cairns. Pulling the strings: A theory of puppetry for the gaming experience. In S. Günzel, M. Liebe, and D. Mersch, editors, Conference Proceedings of the Philosophy of Computer Games 2008, pages 308-323, 2008.

[3] E. H. Calvillo-Gámez, P. Cairns, and A. L. Cox. Assesing the core elements of the gaming experience. In Evaluating User Experience in Games. Springer, London, UK, Forthcoming (2009).
[4] J. Dewey. Experience and Education. Touchstone, New York, U.S.A., 1997.

[5] A. Dix. Designing for appropriation. In D. Ramduny-Ellis and D. Rachovides, editors, Proc. of HCI 2007, volume 2, pages 27-30, Lancaster University, UK, September 2007. British Computer Society.

[6] J. Gee. What video games have to teach us about learning and literacy. Palgrave Macmillan, New York, USA, 2003.

[7] F. Herzberg. One more time: How do you motivate employees? Harvard Business Review, 46(1):53-62, Jan/Feb 1968.

[8] J. Huizinga. Homo-Ludens: A Study of the Play Element in Culture. Beacon Press, London, UK, 1950.

[9] R. J. Jacob, A. Girouard, L. M. Hirshfield, M. S. Horn, O. Shaer, E. T. Solovey, and J. Zigelbaum. Reality-based interaction: a framework for post-wimp interfaces. In CHI '08: Proceeding of the twenty-sixth annual SIGCHI conference on Human factors in computing systems, pages 201-210, New York, NY, USA, 2008. ACM.

[10] J. Juul. Half-Real: Video Games Between Real Rules and Fictional Worlds. The MIT Press, Cambridge, MA, USA, 2005.

[11] M. Kuniavsky. User Experience and HCI. In A. Sears and J. A. Jacko, editors, The Human-Computer Interaction Handbook: Fundamentals, Evolving Technologies, and Emerging Applications, 2nd Edition. Lawrence Erlbaum Associates Inc, New York, USA, 2007.

[12] N. Lazzaro. Why we play games: Four keys to more emotion without story. In Games Developer Conference, Sn. Fco, CA, USA, 2004.

[13] N. Lazzaro. Why we play games together: The people factor. Available at http://xeodesign.com/ (as of sept. 06), XEODesign Inc., 2005.

[14] J. McCarthy and P. Wright. Technology as Experience. The MIT Press, Cambridge, MA, USA, 2004.

[15] D. Michael and S. Chen. Serious games: Games that educate, train, and inform. Muska \& Lipman/Premier-Trade, 2005.

[16] J. Nielsen. Usability Engineering. AP Professional, 1993.

[17] D. Norman. The Design of Everyday Things. BasicBooks, New York, USA, 2nd edition, 2002.

[18] J. Raskin. The Humane Interface: New Direction for Designing Interactive Systems. ACM Press, 2000.

[19] A. Rullo. The soft qualities of interaction. ACM Trans. Comput.-Hum. Interact., 15(4):1-25, 2008.

[20] J. H. Salisbury and R. E. Fields. Why are videogames engaging? determining what we mean by 'fun' with a grounded theory approach. In Twelfth European Conference on Cognitive Ergonomics, 2004.

[21] P. Wright, J. Wallace, and J. McCarthy. Aesthetics and experience-centered design. ACM Trans. Comput.-Hum. Interact., 15(4):1-21, 2008.

[22] P. Zaphiris and C. S. Ang. HCI issues in Computer Games. Interacting with Computers, 19:135-139, 2007. 